\title{
Standardized follow-up program may reduce emergency room and urgent care visits for patients undergoing radical prostatectomy
}

\author{
Ryan Kendrick Flannigan, MD; ${ }^{*}$ Geoffrey T. Gotto, MD, FRCSC; ${ }^{\dagger}$ Bryan Donnelly, MD, FRCSC; ${ }^{\dagger}$ \\ Kevin V. Carlson, MD, FRCSC ${ }^{\dagger}$
}

"Department of Urologic Sciences, University of British Columbia, Vancouver, BC; ' Southern Alberta Institute of Urology and The Division of Urology, Department of Surgery, University of Calgary, Calgary, AB

Cite as: Can Urol Assoc J 2014;8(7-8):e505-9. http://dx.doi.org/10.5489/cuaj.1655

Published online July 18, 2014.

\section{Abstract}

Introduction: The objective of the current study was to determine the impact of a standardized follow-up program on the morbidity and rates of hospital visits following radical prostatectomy (RP) in a tertiary, non-teaching urologic centre.

Methods: Patients who underwent a RP in 2008 were retrospectively evaluated in this study. Postoperative morbidity for the entire cohort was assessed using the Modified Clavien Scale (MCS). Those patients readmitted to hospital or who visited an urban or rural emergency department (ED) within 90 days of surgery were further evaluated to determine the reason for readmission.

Results: At our centre, 321 patients underwent RP in 2008 by 11 surgeons. Of the 321 patients, 77 (24.0\%) visited an ED within 90 days, and 14 were readmitted to hospital, with an additional patient readmitted directly (with a total 15 readmissions, $4.7 \%$ overall). No patients died within the study period. In 2009 we launched a pilot study wherein 115 RP patients received scheduled and on-demand follow-up care by a dedicated nurse between May and November. We found that 90-day readmission rates among this cohort dropped to $5 \%$ and $2.6 \%$ for ED visits and hospital readmission, respectively.

Conclusions: At our tertiary non-teaching centre, a significant number of patients presented back to hospital within 90 days following RP. Most of these patients $(80.8 \%)$ were managed entirely through an outpatient $E D$, and many visits were for routine postoperative care. Only $18.2 \%$ (4.7\% of the 321 prostatectomy patients) were readmitted to hospital. These data point to a need for enhanced postoperative support of patients to reduce costly and often unnecessary visits to acute care EDs. This conclusion is supported by our early experience. Limitations include retrospective design, and variability in practice of surgeons in this study.

\section{Introduction}

The most common form of active treatment for prostate cancer is surgery, notably radical prostatectomy (RP). ${ }^{1}$ This may be conducted in an open, laparoscopic, or roboticassisted laparoscopic fashion. As with any surgery, immediate, early and late complications may occur, with resulting short-term and long-term consequences. ${ }^{2}$ Long-term consequences include urinary incontinence, erectile dysfunction and disease recurrence. ${ }^{3}$ Short-term consequences include cardiovascular complications, venous thromboemboli, rectal injuries and wound infection. ${ }^{4}$ The rate of any one of these short-term complications is reported to be between $28 \%$ and $35 \%$ in a American study. ${ }^{5}$ Alibhai and colleagues reported miscellaneous medical and surgical complication rates of $3.9 \%$ and $5.2 \%$, respectively; these include a variety of potential diagnoses ranging from fever to encopresis and nerve damage. The reported rate of specific urologic complications, including catheter malfunction, urinary tract infection (UTI), bladder neck contracture, and urinary retention was $7.5 \% .^{2}$ Most reports on morbidity and mortality following RP primarily stem from academic institutions, with a few Canadian studies.

The Calgary urology group acts as a tertiary referral centre; however, it is not a resident teaching program. In 2008 (the year under study), the group consisted of 12 adult urologists who performed RPs (11 in an open fashion and 1 laparoscopically).

\section{Methods}

\section{Retrospective review}

All patients who underwent a RP in 2008 were retrospectively included and evaluated in this study. No patients were excluded. Patients' medical and electronic charts were 
reviewed. Individual surgeon practice varied; however, routine care involved discussing the expected postoperative course with the patient. Patients were instructed to have the staples removed by their respective general practitioner or in clinic at each surgeon's preference of timing (7-14 days). Similarly, patients were instructed to return to clinic in 10 to 14 days for Foley catheter removal and for initial clinic follow-up 6 to 12 weeks postoperatively.

Postoperative morbidity for the entire cohort was assessed using the Modified Clavien Scale (MCS), where patients were categorized 0 through 5 (Table 1). ${ }^{6}$

Those patients readmitted to hospital or who visited an urban or rural emergency department (ED) within 90 days of surgery were further evaluated to determine reason for readmission. Patients were identified by the Calgary Health Region's department coding for RP; these patients were then tracked to any inpatient or outpatient readmission to a health centre in the Calgary Healthy Region. These patients were then characterized based upon their reason for ED visit or inpatient readmission, employing the following scale of 1 to 4 ( 1 =surgical complication; $2=$ surgical issue not considered to be a complication; $3=$ routine postoperative care; and $4=$ other medical problem upon reviewed their chart and electronic records).

\section{Prospective pilot}

Based on our initial review of this data, we launched a pilot program wherein a registered nurse was employed to provide standardized postoperative care for patients undergoing RP and cryoablation for prostate cancer. The nurse met with all patients on the ward prior to discharge, and scheduled appointments for Foley catheter removal and staple and/or drain removal if necessary. Patients were able to contact the nurse with telephone queries, which the nurse troubleshot, liaising with the attending surgeon as necessary. A pilot study was conducted prospectively for 115 patients operated on (open RP) over a 7-month period between May and November 2010, by 5 different surgeons. No patients were excluded.

Statistical analysis included a Pearson's Chi-Square to test for differences between the 2008 usual care cohort and the

\begin{tabular}{cl}
$\begin{array}{c}\text { Table 1. The Modified Clavien Scale categories } \\
\text { Category }\end{array}$ & \multicolumn{1}{c}{ Description } \\
\hline 0 & $\begin{array}{l}\text { Normal postoperative course } \\
\text { Any deviation from the normal postoperative } \\
\text { course without needing pharmacological } \\
\text { treatment or surgical endoscopic, and } \\
\text { radiological interventions } \\
\text { Pharmacological treatment with drugs other than } \\
\text { such allowed for grade 1 complications, blood } \\
\text { transfusions and total parenteral nutrition }\end{array}$ \\
2 & $\begin{array}{l}\text { Requiring surgical, endoscopic or radiological } \\
\text { intervention } \\
\text { Life-threatening complication (including central } \\
\text { nervous system complications requiring } \\
\text { intensive care/intensive care unit management } \\
\text { Death of patient }\end{array}$ \\
\hline
\end{tabular}

Taken from Clavien et al. ${ }^{6}$

pilot program cohort. A $p$ value less than 0.05 was considered statistically significant.

\section{Results}

At our centre, 321 patients underwent RP in 2008 by 11 surgeons. Of these, 274 cases $(85.4 \%)$ were done with an open retropubic technique and $47(14.6 \%)$ by laparoscopic technique (non-robotic). The mean patient body mass index was 29.2 (range: 21.5-35.3). Patient length of stay for the original RP averaged 3.76 days (range: $2-10$ ). Seventy-seven patients (24.0\%) presented to an ED 112 times within 90 days, and 14 of these patients were readmitted to hospital, with an additional patient readmitted directly; thus, a total of $15(4.7 \%)$ patients were readmitted. As some of these patients were readmitted more than once, a total of 19 readmissions were identified (Table 2, Fig. 1, Fig. 2). We also compared the usual care 2008 cohort to the 2010 pilot program patients with respect to readmissions and MCS frequency (Table 3). Patients in the pilot program were admitted less frequently $(p=0.02)$, and had less MCS $1(p=0.00)$ and MCS $3(p=0.041)$ events.

The mean length of stay among inpatient readmissions was 4.1 days (range: 1-9). The mean number of days from discharge to patient presentation back to the hospital or ED

Table 2. All patients stratified by MCS score and need for ED visit and/or readmission prior to implementation of pilot program

\begin{tabular}{|c|c|c|c|c|c|c|c|}
\hline \multirow{3}{*}{ Patient group } & \multirow{3}{*}{ n (\%) } & \multicolumn{6}{|c|}{ Complications according to MCS classification } \\
\hline & & \multirow{2}{*}{$\begin{array}{c}\text { None } \\
0\end{array}$} & \multicolumn{2}{|c|}{ Minor } & \multicolumn{2}{|c|}{ Serious } & \multirow{2}{*}{$\begin{array}{c}\text { Death } \\
5\end{array}$} \\
\hline & & & 1 & 2 & 3 & 4 & \\
\hline No readmission or ED visit & $243(75.7)$ & 132 & 91 & 18 & $1^{*}$ & $1^{* *}$ & 0 \\
\hline ED visit only & $63(19.6)$ & 5 & 49 & 4 & 4 & 1 & 0 \\
\hline $\begin{array}{l}\text { Inpatient readmission } \pm \\
\text { ED visit }\end{array}$ & $15(4.7)$ & 0 & 3 & 2 & 8 & 2 & 0 \\
\hline Total (\%) & 321 & $137(42.7)$ & $143(44.5)$ & $23(7.2)$ & $14(4.4)$ & $4(1.2)$ & 0 \\
\hline
\end{tabular}

MCS: Modified Clavien Scale; ED: emergency department. *Required computed tomography intravenous pyelogram to assess urine leak on initial admission.

**Developed acute pulmonary embolism and prolonged hospital stay on initial admission. 


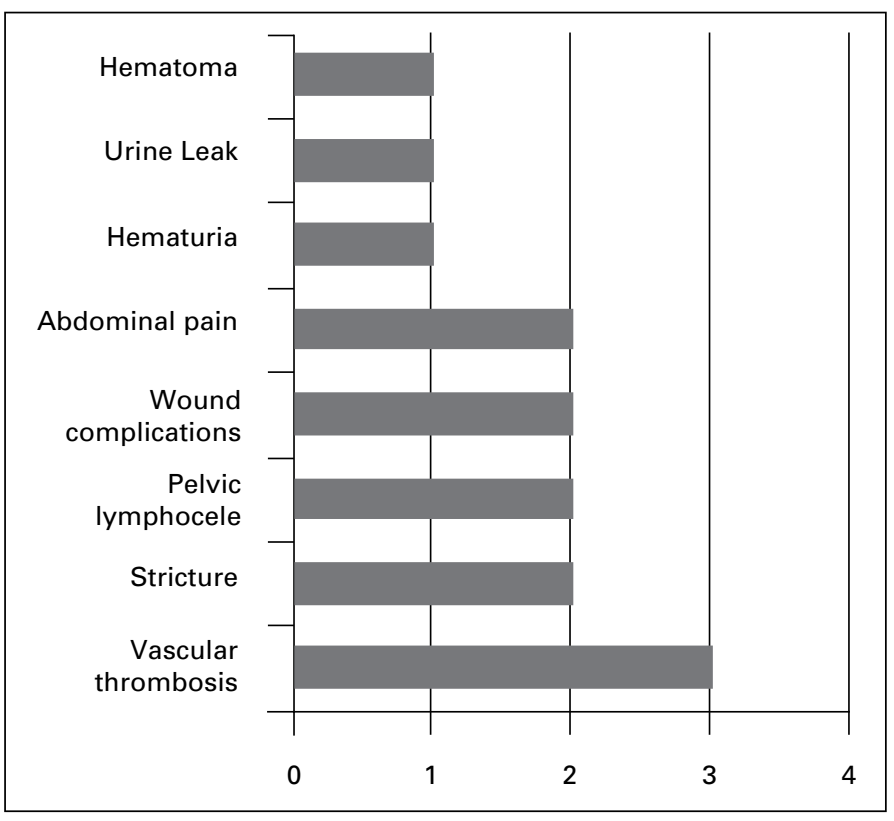

Fig. 1. Primary reasons for readmission to hospital for 15 patients accounting for 19 total readmissions prior to implementation of pilot program. The primary reason for inpatient readmission are demonstrated in this graph.

was 17.9 days (range: $2-81$ ). No patients died within the 90-day postoperative period.

Table 4 details the diagnostic categories of presentations to the ED and/or hospital readmissions. Each hospital presentation was categorized as either a surgical complication (e.g., wound infection, dehiscence, lymphocele), a surgical issue that was not deemed a complication (e.g., bladder spasm, bypassing of urine around a catheter, gross hematuria, urinary retention or $\mathrm{UTI}$ ), routine postoperative care (e.g., staple or Foley catheter removal), or a medical problem unrelated to the surgery (such as a sore toe or asthma attack).

\section{Prospective pilot data}

A total of 115 patients undergoing RP were followed, and 226 visits and/or phone calls were logged. Eighty-four

\begin{tabular}{|c|c|c|c|c|}
\hline & Usual care & $\begin{array}{c}\text { Pilot } \\
\text { program }\end{array}$ & $\begin{array}{l}\text { Chi- } \\
\text { square } \\
\text { value }\end{array}$ & $p$ value \\
\hline $\mathbf{n}$ & 374 & 89 & - & - \\
\hline Mean age & - & 61 & - & - \\
\hline MCS 1 & 173 & 10 & 36.88 & $<0.001$ \\
\hline MCS 2 & 28 & 9 & 0.67 & 0.410 \\
\hline MCS 3 & 25 & 1 & 4.9 & 0.041 \\
\hline MCS 4 & 5 & 0 & 1.2 & 0.270 \\
\hline $\begin{array}{l}\text { ED or inpatient } \\
\text { readmission }\end{array}$ & 131 & 20 & 5.16 & 0.020 \\
\hline
\end{tabular}

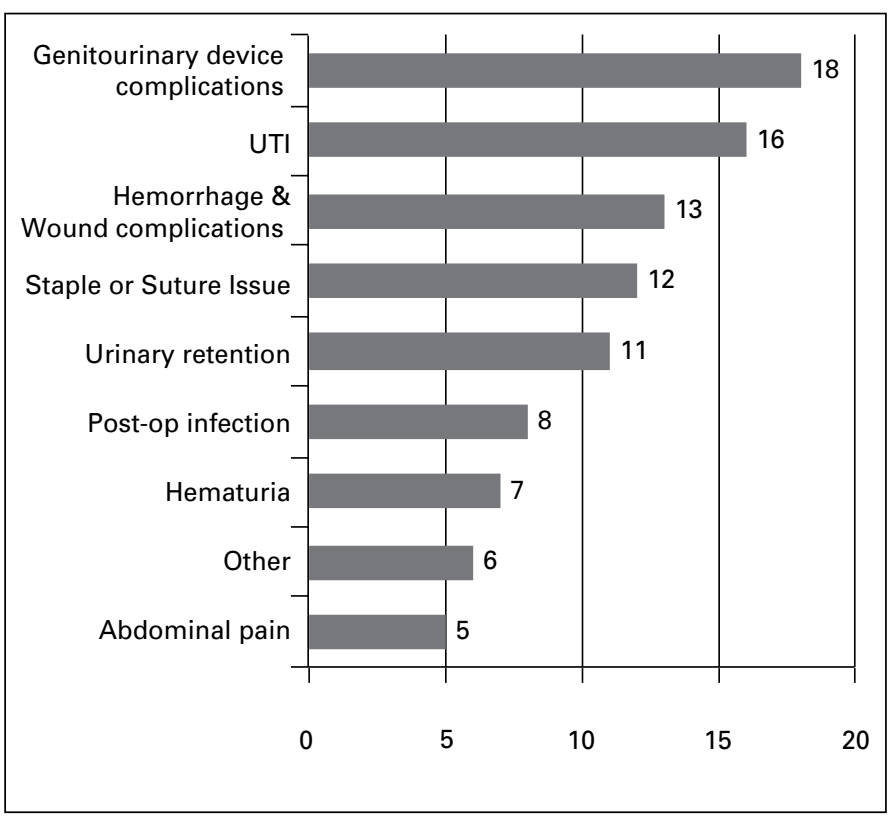

Fig. 2. Reason for emergency room (ER) visit for subset of 96 patients who presented to the ER but did not require readmission to hospital prior to implementation of pilot program.

catheter removals and 18 staple removals were performed. Patients were followed for a minimum of 90 days post-treatment. Only 6 patients (5\%) presented back to hospital within 90 days of surgery, and 3 patients $(2.6 \%)$ were admitted (1 for dehiscence, 1 for UTI and 1 for jaundice [Gilbert's syndrome]).

\section{Discussion}

We found that 90-day morbidity following RP at our institution predominantly reflected minor complications (MCS grade 1-2). More serious complications (MCS grade 3-4) were uncommon, and no deaths occurred over the study period. Returns to hospital within this period, however, were common. This is consistent with previous publications by other academic teaching centres. ${ }^{5,7-9}$ In this study, 77 unique patients out of our cohort of $321(24.3 \%)$ were assessed in an ED (19.6\%) and/or readmitted to an inpatient bed (4.7\%) within 90 days of surgery. All told, this group accounted for 112 ED visits and 19 hospital admissions, incurring significant cost to the healthcare system.

The most common reason for ED presentations was routine postoperative care, such as staple removal (30.4\% of visits). We suspect that this was likely related to a deficit in communication between the surgeon and patient, as routine care included a return to clinic or a follow-up visit with their family physician. The next most common reasons for ED visits were surgical issues not considered a complication (29.5\%), such as catheter-related concerns, hematuria, UTI or urinary retention. Surgical complications $(26.8 \%)$ were 
Flannigan et al.

\begin{tabular}{|c|c|c|c|c|}
\hline \multirow[b]{2}{*}{ Patient group } & \multirow[b]{2}{*}{ Surgical complication } & \multicolumn{2}{|c|}{ Visit reason } & \multirow[b]{2}{*}{$\begin{array}{l}\text { Other medical problem } \\
\text { unrelated to surgery }\end{array}$} \\
\hline & & $\begin{array}{c}\text { Surgical issue not } \\
\text { considered to be a } \\
\text { complication }\end{array}$ & $\begin{array}{c}\text { Routine postoperative } \\
\text { care }\end{array}$ & \\
\hline ED visits & 30 & 33 & 34 & 15 \\
\hline Inpatient readmissions & 14 & 3 & 2 & 0 \\
\hline
\end{tabular}

next most common and included wound dehiscence, lymphocele's, abscess formation, urosepsis or stricture formation. Finally, $13.4 \%$ of patients returning to the ED presented with a medical problem unrelated to surgery (e.g., fracture to the big toe).

Among patients being readmitted to hospital, most were secondary to a surgical complication $(73.7 \%)$, or a surgical issue not considered a complication (15.8\%). Two patients $(10.5 \%)$ had to be readmitted for additional non-surgical postoperative care (1 patient had a defective Foley catheter which required intervention to deflate the balloon, while the other patient was readmitted for a suspected urinary anastomotic leak, but received conservative care and was discharged).

Morbidity as categorized by the MCS is consistent with that from other academic centres. Patients visiting the ED had predominantly less severe complications: 5 (7.9\%) with no deviation in the clinical care pathway, $49(77.8 \%)$ experienced some deviation in care, $4(6.3 \%)$ required pharmacological intervention, $4(6.3 \%)$ required procedural intervention, and $1(1.6 \%)$ had a life-threatening complication. In comparison, most patients readmitted to hospital were more likely to have a true postoperative complication related to surgery and were in need of medical attention. Only $3(20 \%)$ had just minor deviation in care, $2(13.3 \%)$ required pharmacological intervention, 8 (53.3\%) required procedural intervention, and $2(13.3 \%)$ had life-threatening complications. Among the patients that did not seek an ED visit or readmission, the vast majority, 132 (54\%) patients, did not suffer any deviation from routine postoperative care. However, 1 patient requiring a computed tomography urogram to assess a urine leak on initial admission and as such was classified as a MCS 3. One patient developed a pulmonary embolism requiring prolonged 14-day hospital stay warranting a MCS 4.

The above data suggest that a significant number of patients relied on acute care emergency rooms for postoperative care and may have benefited from enhanced outpatient support and resources. Our early pilot data confirm that having a trained nurse available to address patient concerns and deal with routine postoperative care requirements can dramatically reduce visits to the emergency room following RP, particularly with MCS 1 complications. In fact, over the pilot period, only $5 \%$ of patients presented to the ED or urgent care opposed to $24 \%$ in the historical usual care group. This is likely due to the ability to field questions and to provide guidance and reassessments in a very timely fashion and within the urology clinic resources. This early assessment and intervention may partially explain the fewer MCS 3 events in the pilot cohort, as these patients may have been intervened upon before their clinical issues worsened (e.g., treating a simple UTI prior to becoming a febrile UTI requiring hospital stay or parenteral antibiotics, or adjusting a malfunctioning catheter prior to obstructing and causing a urine leak). We have since expanded the pilot program and invited all members of our division to participate.

This study is limited in its retrospective nature, and in the variability in the practices of a moderate-sized cohort of surgeons; however, it is an insightful look at real world experience. Furthermore, while surgical practices among our group have shifted towards increasing sub-specialization and the performance of robotic-assisted laparoscopic prostatectomy in the past 5 years, it provides a historical comparator as we evaluate the impact of these practice changes.

\section{Conclusions}

This study uniquely reflects practice in a tertiary nonteaching centre. A significant number of patients presented back to hospital within 90 days following RP. Most of them $(80.8 \%)$ were managed entirely through an outpatient ED, and many of these visits were for routine postoperative care. Only $4.7 \%$ of the 321 prostatectomy patients were readmitted to hospital. These data point to a need for enhanced postoperative support of patients to reduce costly and often unnecessary visits to acute care EDs. This conclusion is supported by our early pilot experience employing centralized postoperative nursing care.

Competing interests: Dr. Flannigan and Dr. Donnelly all declare no competing financial or personal interests. Dr. Carlson is a member of the Advisory Boards for Astellas and Pfizer and has received payment from these companies. He is currently participating in a clinical trial on behalf of Cook MyoSite. Dr. Gotto is part of the Advisory Boards for Amgen, Janssen and Astellas. He has also received grants from Amgen, Janssen, Astellas and Sanofi.

Acknowledgements: The authors would like to acknowledge Louise Thompson, RN, and The Prostate Cancer Centre for their assistance. 
This paper has been peer-reviewed.

\section{References}

1. Yan Y, Carvalhal G, Catalona W, et al. Primary treatment choices for men with clinically localized prostate carcinoma detected by screening. Cancer 2000;1122-30. http://dx.doi.org/10.1002/(SICI) 1097. 0142(20000301)88:5<1122::AID-CNCR24>3.0.C0;2-Q

2. Alibhai $S M H$, Leach $M$, Tomlinson $G$, et al. 30-day mortality and major complications after radical prostatectomy: Influence of age and comorbidity. J Nat Cancer Institute 2005;97:1525-32. http://dx.doi. org/10.1093/inci/dij313

3. Stanford IL, Feng Z, Hamilton AS, et al. Urinary and sexual function after radical prostatectomy for clinically localized prostate cancer: The Prostate Cancer Outcomes Study. JAMA 2000;283:354-60. http:// dx.doi.org/10.1001/jama.283.3.354

4. Lu-Yao GL, McLerran D, Wasson J, et al. An assessment of radical prostatectomy. Time trends, geographic variation, and outcomes. The Prostate Patient Outcomes Research Team. JAMA 1993;269:2633-6. http://dx.doi.org/10.1001/jama.1993.03500200047031
5. Begg CB, Riedel ER, Bach PB, et al. Variations in morbidity after radical prostatectomy. N Engl J Med 2002;346:1138-44. http://dx.doi.org/10.1056/NEJMsa011788

6. Clavien P, Sanabria J, Strasberg S. Proposed classification of complication of surgery with examples of utility in cholecystectomy. Surgery 1992;111:518-26.

7. Chung SD, Kelle JJ, Huang CY, et al. Comparison of 90-day re-admission rates between open retropubic radical prostatectomy (RRP), laparoscopic RP (LRP) and robot-assisted laparoscopic prostatectomy (RALP). BJU Int 2012;110:966-71. http://dx.doi.org/10.1111/i.1464-410X.2012.11183.x

8. Rabbani F, Yunis LH, Pinochet R, et al. Comprehensive standardized report of complications of retropubic and laparoscopic radical prostatectomy. Eur Urol 2010;57:371-86. http://dx.doi.org/10.1016/i. eururo.2009.11.034

9. Lu-Yao GL, Albertsen P, Warren J, et al. Effect of age approach on complication and short-term mortality after radical prostatectomy - a population-based study. Urology 1999;54:301-7. http://dx.doi. org/10.1016/S0090-4295(99)00100-4

Correspondence: Dr. Kevin V. Carlson, Southern Alberta Institute of Urology, Division of Urology, Department of Surgery, University of Calgary, Calgary, AB; kevin.carlson@albertahealthservices.ca 